\title{
ESTUDO DE CASOS NA FORMAÇÃO DE PROFESSORES DE QUÍMICA
}

\author{
Antonio Narcisio Pinheiro, Ethanielda de Lima Medeiros e Alcineia Conceição Oliveira* \\ Departamento de Química Analítica e Físico-Química, Universidade Federal do Ceará, Campus do Pici, 60000-000 Fortaleza - \\ CE, Brasil
}

Recebido em 4/2/10; aceito em 11/5/10; publicado na web em 9/8/10

\begin{abstract}
CASE STUDIES IN CHEMISTRY TEACHER EDUCATION. Case studies were used as teaching methodology in Chemistry teacher education. The reffered methodology consists of teaching principles of Physical Chemistry associated to biodiesel theme in an undergraduate chemistry course with pre-service teachers, who are temporary teachers in high schools in Fortaleza, Ceará, Brazil. The results showed that the methodology was well accepted by the pre-service teachers. The concepts related to Chemistry, by means of multidisciplinary science, technological and social approaches make it able to overcome and improve the present situation in public schools and provided the learning of the chemistry concepts by high school students.
\end{abstract}

Keywords: chemistry education; case studies; public schools.

\section{INTRODUÇÃO}

Os aspectos conceituais da Química no ensino superior e médio, geralmente, são apresentados aos alunos de forma a não estabelecer relações com suas origens científicas nem tampouco com o contexto social ou tecnológico, na maioria dos estabelecimentos escolares. Desta forma, diversos autores relataram os obstáculos no Ensino de Química, destacando-se o fato de que há uma separação entre as comunidades científica e escolar e isto não contribui para a compreensão do conhecimento e dos processos de ensino- aprendizagem. ${ }^{1-6}$ Por outro lado, há tentativas bem sucedidas de aproximar conceitos científicos com a "Química de sala de aula", através de analogias, contextualização, experimentação e uso do cotidiano para o ensino desta ciência, no ensino médio. ${ }^{3,4}$

Os pesquisadores em Ensino de Química, de modo geral, concordam que as ações didático-pedagógicas devem contemplar o pensamento do aluno, os conceitos de significação, além dos aspectos sócio-científicos, tais como questões ambientais, políticas, econômicas, éticas, sociais e culturais relacionadas à tecnologia e ciências, tanto no ensino superior como do ensino médio. ${ }^{5}$

No entanto, o que se observa no meio educacional é a dificuldade que nosso país enfrenta em formar professores que possam responder às necessidades do ensino superior $\mathrm{e}$, consequentemente, do ensino médio. Isto se reflete na proliferação de metáforas e analogias que deveriam ter um papel fundamental para o ensino de ciências, entretanto, o uso errôneo das mesmas produz um rompimento com o senso comum cotidiano e resulta em distorções do conhecimento científico ${ }^{6}$ este último assume significados completamente díspares em relação ao original, em sala de aula. Adicionalmente, os docentes formados dentro do meio acadêmico (o professor-pesquisador) ou mesmo no campo profissional específico da licenciatura, na maioria das vezes, têm vivências muito diferentes daquelas que encontrarão em sala de aula; portanto, eles não tiveram a oportunidade de refletir e avaliar a atividade profissional que acabam exercendo: o de serem professores. ${ }^{2}$

As consequências naturais do problema relatado são o Ensino tradicional da Química que concebe o ato de ensinar como saber um pouco de conteúdo específico e utilizar algumas técnicas pedagógicas. ${ }^{1}$ Nessa perspectiva, muitas sugestões e tentativas têm sido feitas para tentar resolver este grave problema nacional, através das mais variadas

*e-mail: alcineia@ufc.br formas e proposições, a fim de tornar o Ensino de Química no ensino superior mais estimulante para os alunos. ${ }^{7-9} \mathrm{O}$ objetivo final é fazer o corpo discente compreender e explicar muitas observações que até então se limitavam a aceitar, no estudo da Química. Isto refletirá, posteriormente, no modo com o qual o professor trabalha as teorias, princípios, regras e resultados experimentais (aspectos científicos) em sala de aula, a fim de tornar tais aspectos mais interessantes para facilitar o ensino-aprendizagem, no ensino superior. Apesar de muitos estudos relatarem a origem do que conduz à fragmentação do conhecimento científico e escolar, destaca-se que os docentes, no exercício de suas atividades, não aplicam as soluções/sugestões apresentadas, por tal atividade exigir a contínua atualização científica, humanística e técnica.

Nessa perspectiva, o método do estudo de casos vem se configurando como eficiente no que se refere à aprendizagem de aspectos científicos e tecnológicos no ensino superior, embora não seja tão utilizado no curso de Química, principalmente, em Físico-Química. ${ }^{10-15}$ Nas outras sub-áreas e/ou áreas correlatas da Química, o método do estudo de casos é amplamente difundido e esta metodologia oferece aos graduandos a "oportunidade de direcionar a aprendizagem de assuntos científicos enquanto exploram a ciência envolvida em situações realmente complexas" $;{ }^{10}$ isto se refletirá, posteriormente, nas suas ações como professor.

Desta forma, numerosos trabalhos utilizaram o método do estudo de casos no Ensino de Química e demonstraram que os estudantes graduandos conseguem desenvolver habilidades de pensamento crítico em assuntos de conteúdo científico, tecnologia e sociedade (aspectos éticos, sociais e econômicos) na resolução de casos, além de assimilar o conteúdo das disciplinas em questão. ${ }^{16,17}$

\section{APLICAÇÃO DO MÉTODO DE ESTUDO DE CASOS NAS DISCIPLINAS DAS ÁREAS CORRELATAS E SUB-ÁREAS DA QUÍMICA}

A aplicação do método de estudo de casos nas disciplinas das sub-áreas de concentração em Química (Geral e Inorgânica, Orgânica, Analítica e Físico-Química), bem como nas áreas correlatas como a Bioquímica e Ciências Ambientais, vem se mostrando eficiente na melhoria do processo ensino-aprendizagem. ${ }^{18-28}$ A resolução de problemas baseados em atividades de laboratório também vem ganhando destaque na Química, através da aplicação da referida metodologia..$^{13,25-29}$ 
Todos os autores, de modo geral, concordam que aplicando a metodologia de estudo de casos as habilidades desenvolvidas pelos estudantes devem relacionar: interpretação das informações químicas e apresentação de argumentos científicos; trabalhos com novos problemas e planejamento de estratégias para solucioná-los e, desenvolvimento de trabalhos em grupos, comunicação, assimilação de informações e organização do tempo disponível para o estudo.

Um levantamento bibliográfico realizado de 1980 a 2009 em periódicos tais como Química Nova, The Chemical Educator, Chemical Education Research and Pratice, International Journal of Educational Development, Journal of Chemical Education, dentre outros, permitiu-nos verificar a existência de 35 trabalhos relacionados ao método de estudo de casos. Destaca-se que a pesquisa realizada engloba trabalhos associados às sub-áreas acima mencionadas. Comparando-se o referido levantamento bibliográfico com aquele realizado por Sá e colaboradores em 2007, ${ }^{10}$ observa-se que nos 2 anos que separam ambos os levantamentos não houve um aumento significativo no número de publicações sobre o tema. O levantamento realizado até 2009 complementa o anterior no que se refere à produção de livros que abordam o método de estudo de casos. ${ }^{17}$

A área de concentração em Química Geral é aquela que contém o maior número de fontes pesquisadas, perfazendo um total de 8 trabalhos. Os recursos metodológicos menos centrados no professor, a introdução de conceitos específicos, bem como o desenvolvimento do pensamento crítico são os principais objetivos das fontes pesquisadas. ${ }^{10,22}$ Nelas, o método de estudo de casos é usado para enfatizar a aprendizagem dos princípios da Química (por exemplo, ligações químicas) com novas concepções pedagógicas. Tópicos que englobam a Química Ambiental, Química Analítica e Físico-Química foram também encontrados em número expressivo. Destaca-se o trabalho relacionado ao tema corrosão, em que estudantes de um curso superior em Química elaboraram argumentos e mostraram a capacidade de tomada de decisão para resolver problemas cotidianos, relativos à Química Ambiental. ${ }^{30}$

Outras sub-áreas como a Química Orgânica e a Bioquímica, associadas ou não, mostraram trabalhos contendo uma abordagem que além de estimular o pensamento crítico dos estudantes visava fornecer subsídios para a resolução de problemas..$^{20,25} \mathrm{~A}$ análise dos efeitos causados pelo medicamento talidomida ${ }^{10,31}$ e sua repercussão é um exemplo bem sucedido de que o método do estudo de casos desenvolve o pensamento crítico e promove o desenvolvimento de discussões e atividades de pequenos grupos, de acordo com a classificação de Herreid. ${ }^{32}$

Além disso, praticamente, inexistem trabalhos relacionados na área da Química Inorgânica, até o momento da pesquisa; porém, tal área de concentração permanece simultaneamente associada com as áreas de Química Geral e Analítica. As áreas correlatas como Química Medicinal, Química Computacional, Química Aplicada à indústria também mostraram, através da interdisciplinaridade, que a Química produz novas alternativas de ensino que promovem o ensino-aprendizagem de tópicos da Química. ${ }^{10}$

Especificamente, na sub-área de Físico-Química são variadas as estratégias utilizadas para a resolução dos casos, tais como tarefa individual, discussão e atividades em pequenos grupos, e é crescente o número de professores que utilizam tal método. ${ }^{10-17} \mathrm{O}$ intuito reside em produzir casos que serão utilizados nas aulas ministradas pelos docentes para atenuar as dificuldades em relação à Matemática e Física, necessárias à compreensão da referida sub-área. Adicionalmente, propostas que investigam os aspectos científicos da química e o ensino em sala de aula são relatadas através da necessidade dos professores utilizarem transposições didáticas, contextualização e interdisciplinaridade..$^{3-5,33-38}$

Por exemplo, o Caso Capital City relaciona conceitos de FísicoQuímica como a termodinâmica e cinética enquanto analisa, em um contexto amplo, as fontes de combustíveis de uma cidade. ${ }^{13}$ Os combustíveis incluem as fontes tradicionais de energia (combustíveis fósseis) e energias renováveis (células a combustível, energia solar, produção de hidrogênio via reforma do metano, energia geotérmica). Através destas, as atividades desenvolvidas foram relativas à discussão dos potenciais energéticos, avaliação das emissões de combustíveis fósseis e a análise da eficiência de novos processos. Os objetivos foram centrados na resolução de problemas, como a influência da temperatura sobre a constante de equilíbrio, cálculos envolvendo ciclo de Carnot e energia livre de Gibbs, determinação de velocidades de reações, medidas eletroquímicas e interconversões de unidades; as habilidades desenvolvidas pelos discentes foram o trabalho de grupo, a comunicação e organização, além da resolução de problemas e pensamento crítico. No entanto, há ainda uma escassez desses dados no que se refere ao ensino de Físico-Química e somente 6 trabalhos que foram categorizados nesta área pautavam o entendimento, objetivos e desenvolvimento das atividades relativas aos estudos de casos.

Neste trabalho, descreveremos um estudo de caso, investigado com alunos graduandos que cursam o ensino superior em Química (licenciatura) e lecionam nas escolas públicas de Fortaleza, Ceará. O estudo tem como objetivo geral aplicar o método do estudo de casos para avaliar os fatores que conduzem à completa disjunção entre os aspectos científicos e tecnológicos da Química e o ensino de sala de aula. Especificamente, a proposta consistiu em analisar as causas da referida fragmentação, bem como apresentar uma proposta alternativa que engloba a interdisciplinaridade envolvida nos conceitos de Físico-Química, através do método do estudo de casos.

A proposta visa aplicar o método do estudo de casos para melhorar o entendimento de conceitos vistos em Físico-Química (tais como, equilíbrio de fases, cálculo estequiométrico, viscosidade, dentre outros).

\section{Metodologia de coleta e análise de dados}

Para alcançar o objetivo citado acima, desenvolveu-se um estudo de caso, denominado de $O$ biodiesel (Quadro I) de caráter facultativo, com 30 estudantes, a partir do $2^{\circ}$ ano de graduação, inscritos na disciplina Físico-Química Básica I, na Universidade Federal do Ceará - UFC. Todos os sujeitos que participaram da pesquisa lecionam disciplinas das áreas de concentração em Química (Química Geral e Inorgânica, Orgânica e, majoritariamente, Físico-Química) através de contratação temporária, nas escolas públicas de Fortaleza.

Através desse método, os licenciandos consultaram artigos sugeridos, dissertações e livros de Físico-Química, ${ }^{10,38-41}$ discutiram-nos em pequenos grupos; posteriormente, cada estudante, individualmente, relatou os problemas que enfrentaria em aplicar os experimentos contidos no artigo descrito por Rinaldi e colaboradores, ${ }^{39} \mathrm{em}$ sala de aula no ensino médio. O referido artigo, intitulado "Síntese do biodiesel: uma proposta contextualizada de experimento para laboratório de Química Geral", trata de experimentos que envolvem o biodiesel e deste artigo foram escolhidos os seguintes experimentos: "Verificando a formação de emulsão e sua estabilidade, Efeito da quantidade de catalisador na síntese do biodiesel, Avaliando o efeito do tempo de transesterificação, Estimando as viscosidades relativas do diesel, biodiesel e óleo de soja e Comparação da queima do biodiesel, do diesel e do óleo de vegetal". ${ }^{39}$ A escolha dos referidos procedimentos experimentais tem o objetivo de enfatizar os conceitos relatados acima e mostrar a interligação das disciplinas das áreas da Química, para os licenciandos, além de permitir que sejam levados em conta os seus conhecimentos prévios.

Nas etapas seguintes, o professor e os alunos propuseram possíveis soluções. Por fim, cada licenciando apresentou em aula expositiva de 50 min alguns tópicos de Físico-Química envolvendo 
Quadro 1. Caso: O biodiesel

\section{O biodiesel}

Durante uma aula de Físico-Química na UFC sobe o tema "Equilíbrio de soluções", licenciandos questionam o professor da disciplina acerca de como poderiam mostrar aqueles conceitos para alunos do ensino médio, visto que parte daqueles estudantes de licenciatura eram professores contratados temporariamente em escolas públicas do município de Fortaleza.

O titular da disciplina recomendou que os estudantes lessem artigos científicos sobre um tema atual e sugeriu, por exemplo, o biodiesel justificando que o Estado do Ceará era detentor de uma grande usina deste biocombustível.

Os estudantes, aparentemente, não compreenderam a relação existente entre a sugestão mencionada e o tópico do conteúdo explicitado durante a aula expositiva. No final da referida aula, alguns estudantes questionaram o professor:

- "Como faremos para ensinar 'equilíbrio de soluções' para os alunos do ensino médio, se nem mesmo nós entendemos o que é esse biodiesel? Vemos todo mundo falar, mas, achamos que é difícil mostrar e passar isso para os alunos do ensino médio, sem laboratório, como é o caso da maioria das escolas que damos aula".

O professor titular responde:

- "Sugiro que pesquisem e leiam sobre o tema e na próxima aula discutiremos sobre o assunto".

$\mathrm{Na}$ aula seguinte, o titular da disciplina, inicialmente, expôs para todos os 35 estudantes presentes sobre as indagações de parte deles na aula anterior e justificou que aquela aula seria lecionada através das discussões sobre o artigo de Rinaldi e colaboradores para melhor compreensão do tópico, bem como mostrar suas aplicações. ${ }^{39}$

Após a leitura do referido artigo, em grupo, os estudantes discutiramno e alguns deles conseguiram correlacionar os tópicos do conteúdo ministrado com o tema biodiesel. A maioria deles mostrou-se surpreso com o novo modo de aula do professor, aprovando-o, mas, os licenciandos não entenderam como aplicar a metodologia aos alunos do ensino médio.

O professor, juntamente com os 30 alunos da classe, decidiu investigar tal dificuldade, minuciosamente e sugerir propostas para solucionar o problema.

o tema biodiesel para a disciplina que lecionava. Tais atividades foram desenvolvidas extra-classe, perfazendo um total de 2 meses para cumpri-las.

Ao final, um estudo minucioso sobre o diagnóstico permitiu-nos tecer considerações sobre as falhas que ocorrem na formação do licenciando e o reflexo de sua atividade docente no Ensino de Química de nível médio, área em que os docentes optaram por se profissionalizar.

Duas etapas do estudo de caso foram cumpridas, integralmente, baseando-se em referências anteriores descritas na literatura: leitura e compreensão de artigos científicos, por parte dos licenciandos que irão lecionar no ensino médio ${ }^{7,10} \mathrm{e}$, capacitação dos licenciandos para a aplicação aos seus alunos, do ensino médio, de novas metodologias de ensino, cujo enfoque privilegiasse aspectos tecnológicos, sociais, econômicos e ambientais da Química. ${ }^{10,38}$

Ao final das etapas acima realizadas, os autores deste trabalho propõem avaliar os resultados obtidos para verificar se houve aproximação entre o conhecimento científico-tecnológico e o exercício do magistério em Química.

A estratégia utilizada consistiu em desenvolver, inicialmente, um diagnóstico acerca do perfil acadêmico e socioeconômico dos licenciandos que lecionam as disciplinas nas escolas públicas de Fortaleza.

Posteriormente, os licenciandos foram convidados a participar da pesquisa, após serem informados sobre as propostas da mesma. Somente 28 estudantes participaram, efetivamente, da consulta. Procuramos também conhecer a trajetória profissional exercida pelo licenciando, através de entrevista e das perguntas apresentadas no Quadro 2, após a realização das etapas iniciais de leitura e capacitação.

Quadro 2. Questionário de avaliação sobre a trajetória profissional exercida pelo licenciando

1. Se na escola que você leciona não tem laboratório de Química, você como professor leva para a sala de aula demonstrações práticas relacionadas ao conteúdo dado e ao cotidiano dos alunos?

2. Como você utilizaria o cotidiano como ferramenta para melhor compreensão (assimilação) dos conhecimentos?

3. O uso de recursos para decorar textos e analogias é necessário para uma melhor memorização do conteúdo?

4. O vestibular é uma medida do conhecimento ou acúmulo de conteúdo?

5. A formação acadêmica é importante na atuação de todo profissional?

6. Você se preocupa em se atualizar para uma melhor atuação profissional?

7. Você encontrou dificuldades para transmitir o conhecimento, utilizando o tema biodiesel?

8. A sua perspectiva em relação aos seus alunos como profissionais é otimista?

9. A escola limita o professor na transmissão do conhecimento?

Por fim, avaliamos os alunos do ensino médio daqueles estudantes de licenciatura aos quais capacitamos. A aplicação da proposta e coleta de dados permitiu-nos a avaliação do Quadro 3, aplicado aos alunos do ensino médio (cerca de 80 estudantes), para cumprimento da etapa final do estudo de caso. Ações de assistência aos licenciandos no desenvolvimento de suas estratégias de ensino e avaliação são propostas.

Quadro 3. Questionário aplicado aos estudantes após os experimentos

1. Você entendeu os experimentos?

( ) $\operatorname{sim}($ ) não ( ) não sei

2. Na sua opinião ficou mais fácil entender a teoria com os novos experimentos realizados?

( ) $\operatorname{sim}($ ) não ( ) não sei

3. Se os professores utilizassem exemplos do cotidiano ou exemplos que serão aplicados na sua vida profissional, isto facilitaria a compreensão dos temas em estudo?

( $) \operatorname{sim}(\quad$ ) não ( ) não sei

4. Dentre as disciplinas previamente estudadas (Química Orgânica, Físico-Química e Inorgânica) você conseguiria associar ao tema biodiesel, a partir dos experimentos realizados?

( ) $\operatorname{sim}($ ) não ( ) não sei

5. Os novos experimentos são adequados às necessidades da escola onde você estuda?

( ) $\operatorname{sim}(\quad$ ) não ( ) não sei

\section{RESULTADOS E DISCUSSÃO}

\section{Capacitação dos estudantes}

Uma análise prévia realizada com os licenciandos revelou, dentre outros aspectos interessantes, o completo desconhecimento do exercício da docência no ensino médio e a pesquisa científica e bibliográfica, de modo que os instrumentos práticos e teóricos do ensino se encontravam dissociados. Na tentativa de corrigir, atenuar ou esclarecer as falhas dos problemas relatados, propusemos aos licenciandos que lecionam no ensino médio uma capacitação para um 
"miniprojeto" - um problema prático que requer para sua solução a aplicação de conceitos e habilidades desenvolvidas em conjunto de experimentos previamente realizados, ${ }^{23}$ para sua posterior aplicação em sala de aula, no ensino médio.

O biodiesel é um tema atual que oferece a oportunidade de trazer para as salas de aula uma metodologia de ensino diferente do tradicional, tornando a aprendizagem mais interessante. O tópico fornece uma abordagem ampla, de vários contextos que podem ser discutidos, incentivando o professor ao longo da abordagem desses temas a trabalhar valores, atitudes e senso críticos dentro da sala de aula, desenvolvendo também a consciência ambiental que o tema propicia. $^{39}$

Esta proposta consistiria em uma boa oportunidade para o licenciando testar as suas competências didáticas, sua capacidade de planejamento e levaria a uma sistemática do Ensino de Química de nível médio, que seria muito vantajosa para o aluno em relação àquelas propostas tradicionais. Parte dos experimentos propostos no artigo de Rinaldi e colaboradores foi realizada ${ }^{39}$ cumprindo-se, integralmente, a proposta apresentada no trabalho. Em linhas gerais, o artigo relatado permitiria realizar um estudo de caso, a fim de conhecer os fatores que distanciam o ensino de sala de aula e o conhecimento científico.

Assim, todos os licenciandos leram o referido artigo e foram submetidos à capacitação mencionada, sendo que os grupos de estudo propuseram a aplicação das sugestões, nas escolas em que lecionavam, utilizando-se materiais simples e de fácil obtenção, para contextualizarem as aulas teóricas e associá-las a temas atuais, como o própio biodiesel. Vale ressaltar que a maioria deles já teve contato com este tipo de recurso, em algumas disciplinas. Após a leitura do texto, observou-se que os licenciandos tiveram a impressão que somente poderiam abordar os tópicos de uma dada sub-área da Química; portanto, só poderiam ensinar os conceitos de Química Orgânica, uma vez que, na opinião deles, o tema biodiesel era dedicado exclusivamente a esta área. Outros autores revelaram a mesma observação, em trabalhos prévios, ${ }^{42-45}$ mostrando que "há uma nítida separação entre a Química Orgânica e as áreas da Química", na opinião dos estudantes de graduação. Posteriormente, o fato sobre a interdisciplinaridade que o assunto conduzia foi esclarecido e, então, discutiram-se os tópicos que poderiam ser abordados dentro do tema biodiesel: 1) funções orgânicas, reações de transesterificação e saponificação (para aqueles licenciandos que lecionavam Química Orgânica); 2) separação de fases, emulsões, termodinâmica e cálculo estequiométrico (para aqueles estudantes que lecionavam Físico-Química) e, 3) ácidos e bases (para aqueles que lecionavam Química Geral e Inorgânica).

Ressalta-se que a definição de biodiesel, forma de obtenção, questões ambientais ligadas ao tema, bem como suas aplicações também deveriam ser enfatizadas; ou seja, o biodiesel seria uma ferramenta para contextualizar, trabalhar valores, atitudes e desenvolver a consciência ambiental, relacionando com o cotidiano dos alunos.

Para os alunos do ensino médio, a escolha da metodologia tem o intuito de que tenham uma visão de ciência, acessível, para que neles seja produzido o devido interesse, através da abordagem de fatores socioeconômicos, políticos e também fatos relacionados à tecnologia.

Desta forma, os licenciandos ensaiaram as aulas, individualmente, para o docente da disciplina e seus colegas; sugeriram-se estratégias inovadoras, pautando-se um maior contato com a realidade da escola de nível médio onde os licenciandos lecionavam e, ao mesmo tempo, oferecendo condições para superarem as deficiências apontadas, previamente, neste trabalho: o completo distanciamento entre os aspectos científico-tecnológico-social da Química com a escola de nível médio.

As soluções apontadas pelos estudantes de licenciatura para a resolução do caso biodiesel (Quadro 1) foram as mais variadas, dentre as quais se destacam o estímulo à leitura de jornais, revistas e o uso de reportagens exibidas pela mídia televisiva e internet sobre o tema, para os alunos do ensino médio. Além disso, as propostas dos licenciandos convergiram para a realização integral dos experimentos supracitados em sala de aula, nas escolas públicas. Destaca-se ainda que as soluções encontradas pelos licenciandos não fixem um método único e exato de solução, de modo similar ao observado em trabalhos anteriores. ${ }^{7}$ Por exemplo, os conceitos relacionados ao cálculo estequiométrico e/ou equilíbrio químico (termodinâmica) formam os pontos mais significantes, segundo a percepção da maioria dos licenciandos, devido aos cálculos serem difíceis, até que eles reconheceram um método novo que facilitou a assimilação dos conceitos. As questões ambientais trouxeram a oportunidade de colocar a "teoria e prática" através do estudo de Físico-Química em um conceito aplicado, por todos os estudantes de licenciatura.

Após a sua capacitação, os licenciandos responderam ao questionário, contido no Quadro 2 e as respostas encontram-se na Figura 1a.

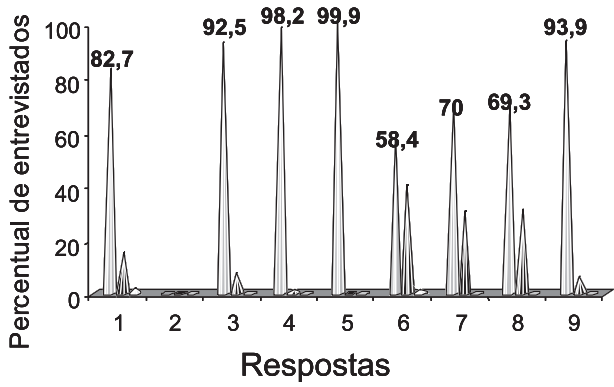

a)

b)

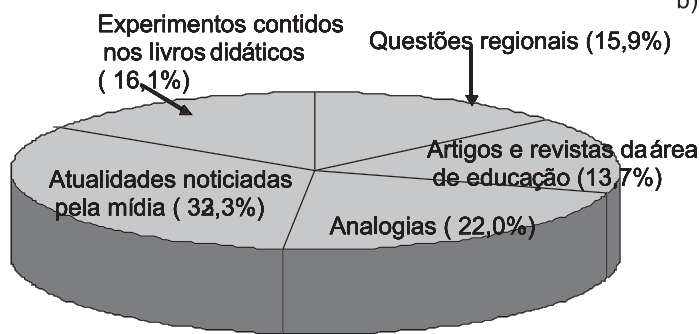

Figura 1. (a) Percentual de estudantes entrevistados em função das respostas dadas ao Quadro 2. (b) Resposta à pergunta 2

A Figura 1a apresenta as respostas relativas ao percentual de estudantes entrevistados, evidenciando que $82,7 \%$ dos licenciandos se preocupam em incluir aulas teóricas e, não raro, práticas relacionadas ao cotidiano, como ferramenta facilitadora do aprendizado dos seus alunos. Registra-se também que a estimativa para aqueles que não o aplicam é de 15,0\%; por outro lado, 2,3\% desconhecem esta metodologia de ensino, perfazendo o conjunto de respostas 1 . Essa última interpretação merece sérios reparos, uma vez que parece ser oriunda da formação acadêmica dos estudantes, inadequada para as necessidades de seus futuros alunos.

Cerca de $16 \%$ do total dos licenciandos mencionaram que as questões regionais são utilizadas como ferramenta para relacionar o cotidiano com os temas vistos em sala de aula, enquanto que $13,7 \%$ usam artigos e revistas científicas para este fim (resposta relativa à questão 2, Quadro 2, representada na Figura 2).

Por outro lado, 22\% dos entrevistados usam analogias relacionadas ao cotidiano para induzirem uma maior aprendizagem, no entanto, reconhecem a dificuldade de conciliar os conceitos expostos na sala de aula com a vivência cotidiana do aluno. Especificamente, para aqueles entrevistados que utilizam recursos do cotidiano como uma metodologia alternativa para o Ensino de Química (resposta 2 relativa à pergunta 2, Quadro 2), na escola de ensino médio, observase que $32,3 \%$ deles utilizam atualidades noticiadas pelos meios de comunicação para ilustrar suas aulas (Figura 1b). 
Destaca-se que $16,1 \%$ dos entrevistados que utilizam materiais triviais para a elaboração de experimentos responderam que a atividade se configura em uma pesquisa que extrapola o laboratório e permite a compreensão de fenômenos químicos encontrados, em diferentes áreas da sociedade, e isto se torna uma ferramenta facilitadora do ensino.

Como um elevado percentual de estudantes emprega as analogias para demonstrar conceitos, nessa oportunidade, colhemos a impressão desses estudantes acerca dessa metodologia para investigar sua eficácia. Assim, é também expressivo o contingente de licenciandos que concorda com o uso deste recurso - 92,5\% - ainda que 6,5\% não aceitem esta ideia (Figura 1a, resposta 3). Porém, ressaltamos que, apesar das analogias ilustrarem o cotidiano, a substituição de conceitos que exijam raciocínio formal por modelos que possam ser manipulados para desenvolver o cognitivo, como as analogias, é duvidosa.

Neste ínterim, a Figura 1, resposta 4, mostra que o vestibular pelo qual os licenciandos passaram, antes de ingressar na universidade, consiste em um acúmulo de conteúdo, de acordo com 98,2\% dos entrevistados, e apenas $1,8 \%$ dos estudantes informaram que este processo seletivo é ilustrativo da medida do conhecimento adquirido durante a sua formação no ensino médio e acrescentaria na sua formação profissional.

Dentro deste contexto, a totalidade $(99,9 \%)$ de estudantes entrevistados respondeu que a formação acadêmica era importante para a sua futura atuação profissional (Figura 1a, resposta 5). Esta resposta é trivial, entretanto, ela foi justificada com vistas às maiores oportunidades para professores de Química, ofertadas no magistério de ensino médio, no Estado do Ceará, fato que tem originado a procura pelo curso de Licenciatura em Química por profissionais já graduados em áreas correlatas.

A visão que os licenciandos apresentaram para a necessidade de se atualizar e a preocupação com o conteúdo a ser lecionado é surpreendente, $58,4 \%$, contra a opinião de $40 \%$ dos entrevistados e $1,6 \%$ daqueles que não sabem (Figura 1a, resposta 6). Por outro lado, $70 \%$ dos licenciandos revelaram que têm dificuldade para transmitir os conhecimentos sobre o tema biodiesel, justificando que o assunto requer dos professores amplos conhecimento e criatividade na abordagem do tema a ser trabalhado em sala de aula, enquanto que $30 \%$ não tiveram dificuldade (resposta 7 , Figura 1a). Os estudantes de licenciatura também ressaltaram que a inexistência de infraestrutura adequada nas escolas públicas para as aulas práticas dificulta o entendimento do tema exposto.

Os estudantes que participaram do estudo de caso também relataram que as ideias em relação aos conceitos de Físico-Química, relacionando-os com a Química Orgânica, Química Geral e Inorgânica que foram discutidos e aplicados são inovadoras, de fácil compreensão.

Com o propósito de verificar sobre as perspectivas futuras dos licenciados em relação ao futuro profissional de seus alunos, pergunta 8 do Quadro 2, mais de 1/3 dos licenciandos responderam que a sua perspectiva era otimista (resposta afirmativa à pergunta 8) e eles acreditavam que os seus alunos seriam inseridos no mercado de trabalho, caso se esmerassem em seus estudos. Entretanto, 69,3\% dos entrevistados justificaram em uma perspectiva negativa (resposta negativa à pergunta 8) o baixo desempenho e/ou a evasão associados aos estudantes de escolas públicas, que resultaria na não atração do mercado de trabalho por estes futuros profissionais, tanto em número de oportunidades, quanto as perspectivas salariais, contra a opinião de $30,7 \%$ dos entrevistados (Figura 1a, resposta 8).

Eles acrescentaram que todo profissional ligado ao Ensino de Química deve promover a evolução conceitual dos alunos, através de debates, discussões, especulações, lançando desafios para a evolução das ideias dos estudantes e, por conseguinte, o reflexo do trabalho realizado em sala de aula seria a formação de um bom profissional; isto configura o papel do educador como mediador de tal construção e da escola. ${ }^{24,28}$

Os licenciandos $(93,9 \%)$ responderam positivamente que a escola limita o professor na transmissão do conhecimento, contra a opinião de $6,1 \%$ dos entrevistados (resposta 9, Figura 1a). Avaliando o número de estudantes que responderam afirmativamente à questão, inferimos que o sistema educacional ao qual os estudantes estão vinculados impõe a eles uma sistemática que induz a um modelo de escola, falida, que é resultante de um sistema de aprovações automáticas do aluno, para se ter números significativos de melhoria da qualidade do ensino médio. Ressalta-se que este dado é uma realidade local que deve ser modificada; entretanto, deve-se considerar que os autores apenas tiveram informações sobre o problema exposto. Portanto, não foi possível associar tal resultado ao objetivo do nosso trabalho, o que poderia resultar em uma conclusão pouco diferente da aqui exposta.

\section{Aplicação da metodologia para os estudantes do ensino médio}

Os licenciandos solicitaram de seus alunos materiais triviais, tais como óleo de soja, fósforo, papel toalha, sal de cozinha, detergente, água, álcool etílico (advindo da secretaria da escola) e copos descartáveis. Os estudantes de licenciatura levaram da Universidade materiais como pipetas graduadas, tubos de ensaio, lamparina, pinças, agitador magnético e reagentes, tais como hidróxido de sódio e potássio, metanol, hexano e óleo diesel, uma vez que nas escolas avaliadas não havia laboratórios para as aulas experimentais.

Em seguida, os experimentos foram aplicados nas aulas de FísicoQuímica, Química Orgânica e Química Geral e Inorgânica em que aqueles licenciandos lecionavam, conforme descrito anteriormente. Todos os licenciandos aplicaram suas propostas didáticas no ensino médio da mesma forma, como resposta ao estudo de caso. As aulas formam assistidas e transcritas, constituindo-se em material empírico para posterior análise pelos próprios estudantes de licenciatura e para avaliação dos autores deste trabalho. Os estudantes de nível médio afirmaram que entenderam os experimentos e os conceitos associados a eles, segundo $88,5 \%$ do total de entrevistados. Cerca de $7 \%$ dos estudantes de ensino médio mostraram dúvida quanto aos aspectos do conteúdo enunciados através da experimentação, enquanto que $3,8 \%$ não a compreenderam de acordo com as respostas à pergunta do Quadro 3 (resposta 1, Figura 2).

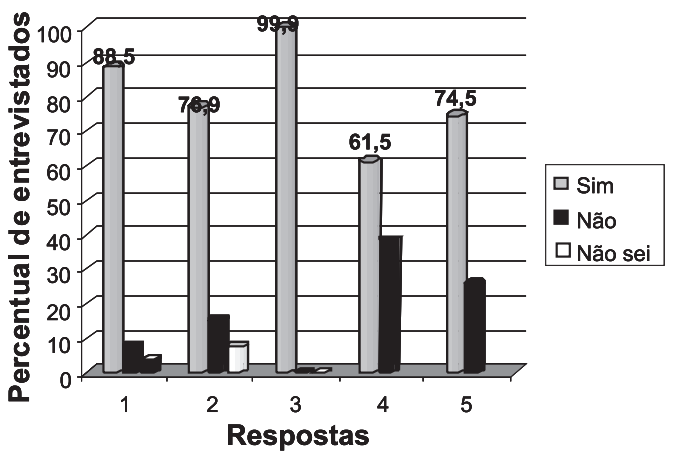

Figura 2. Percentual de estudantes entrevistados em função das respostas dadas ao Quadro 3

Os alunos do ensino médio responderam, em seus depoimentos, que o entendimento da teoria é facilitado pela experimentação (76,9\%), contra a opinião de $15,4 \%$, conforme observado na resposta 2 , Figura 2. Este percentual relativamente alto, associado com aquele percentual de estudantes que tiveram dúvida acerca dos conceitos 
teóricos $(7,7 \%)$ revelam os fatores que separam os aspectos científicos e tecnológicos da Química com o ensino em sala de aula: a forma como o conteúdo é abordado nos livros didáticos e na sala de aula mostra um método arcaico de ensino que enfatiza mais os aspectos conceituais e qualitativos, fato que ainda se encontra enraizado no pensamento de uma boa parcela dos alunos-alvo desta metodologia.

Em contraste, a totalidade (resposta 3, Figura 2) de estudantes do ensino médio afirmou que as vivências cotidianas associadas à abordagem dos assuntos facilitam o aprendizado, provavelmente devido à euforia causada pela sensação de descobrir uma novidade através da experimentação.

Aproximadamente, $61,5 \%$ dos entrevistados não conseguiram associar as disciplinas das sub-áreas da Química, Físico-Química, Química Orgânica e Química Geral e Inorgânica, através da experimentação, contra $38,4 \%$ do total daqueles que não sabem ou não entenderam, segundo o conjunto de respostas 4, na Figura 2. A dificuldade de associar o tema e entender a interdisciplinaridade, por parte dos alunos de ensino médio, foi o reflexo do despreparo e da falta de domínio do assunto por parte dos licenciandos, principalmente quanto ao cálculo estequiométrico.

Ainda ressaltamos que $74,5 \%$ dos estudantes consideram a nova prática pedagógica como adequada as suas necessidades; por outro lado, 25,5\% (Figura 2, resposta 5) não têm a mesma opinião formada a respeito da referida questão, devido à distância do tema e a sua realidade e este fato é relatado aqui da seguinte forma:

"Eu nem sabia que esse biodiesel que todo mundo fala aí, foi inventado aqui no Ceará. Agora, entendo o que é a função Éster. $O$ biodiesel é um produto fácil de se obter como, por exemplo, pelo óleo vegetal usado na cozinha e etanol ou metanol. Também é um produto químico que polui menos o ar atmosférico que o diesel, um hidrocarboneto derivado do petróleo" (observação feita por um estudante que cursa a $3^{\mathrm{a}}$ série do ensino médio, após a aula de Química Orgânica).

"A aula de Físico-Química ficou mais fácil porque agora já sei por que fazer tanto cálculo para melhor compreender os fenômenos através do balanceamento de equações, como essa da formação do sabão... também, entendi que a produção de biodiesel no nosso Estado pode fixar o homem no campo, evitando o inchaço populacional das grandes cidades" (observação feita por um estudante que cursa a $2^{\mathrm{a}}$ série do ensino médio, após a aula de Físico-Química).

De modo geral, observamos que a abordagem do assunto biodiesel transformou a realidade escolar, aproximando-a da ciência química e tecnologia, e fato mais importante, relacionado-a com a sociedade. Tudo isso contribuiu como ferramenta facilitadora da aprendizagem do aluno de ensino médio, que recebeu a proposta com interesse e satisfação. Os posteriores exames de avaliação que os estudantes do ensino médio foram submetidos nas disciplinas investigadas, com aplicação de questões conceituais e contextuais, revelaram que o desempenho dos discentes melhorou progressivamente.

\section{Avaliação do desempenho dos licenciandos e sugestões propostas}

Os resultados obtidos mostraram que houve uma preocupação, por parte dos licenciandos, em contextualizar, unir, associar as questões da ciência, tecnologia e sociedade que o tema biodiesel permite. No entanto, observou-se que os licenciandos, como professores, privilegiam a ênfase dos aspectos teóricos, com vistas a mostrar o conteúdo; tal observação é oriunda talvez da formação acadêmica que estes docentes vêm recebendo, revelando uma falta de autonomia para romper com o tradicional. Houve também deturpação de alguns conceitos, introdução de conteúdos alheios ao tema ao proposto, o biodiesel, o que significa um nível de aprendizagem e formação acadêmica deficiente daqueles estudantes ao qual capaci- tamos. Admitimos também que a capacitação aplicada bem como o fato de que os licenciandos ainda estão em formação não permitem esperar resultados completamente satisfatórios, quanto à melhoria do ensino-aprendizagem.

Os licenciandos destacaram também que o perfil do aluno de graduação em Química sugerido pelas DCN (Diretrizes Curriculares Nacionais para os Cursos de Química) não era compatível com a sua formação que prioriza a aula expositiva, o livro texto e as listas de exercício como técnicas de ensino para o desenvolvimento da aprendizagem em sala de aula. ${ }^{45,46}$ Outros relataram que as aulas de demonstração, seminários, planejamento das aulas, método de projetos e outros instrumentos de avaliação, além da prova, melhoraram a sua formação; adicionalmente, os recursos informatizados, associados às citadas metodologias tradicionais, também eram aplicados por alguns professores, segundo os relatos de alguns licenciandos.

Os autores entendem que esta é uma herança herdada da formação que os licenciandos tiveram no ensino médio, de caráter única e exclusivamente teórico ao qual se vinculam conhecimentos dissolvidos e negligencia o caráter investigativo, sem desenvolver o espírito crítico do estudante. Isto reflete em um currículo inadequado da escola de nível médio, que deve ser corrigido no ensino superior; quando tal imperfeição é corrigida ou atenuada, eles retornam à escola de ensino médio, como professores, os quais são, em grande parte, despreparados, mal remunerados, com carga horária elevada e utilizam livros didáticos que não relatam experiências simples e palpáveis. Consequentemente, tem-se uma escola inapropriada para receber os alunos desses professores e, principalmente, com relação à realização de trabalhos experimentais.

Apesar de que a metodologia proposta pode ser aplicada rotineiramente nas escolas públicas, a inclusão de práticas pedagógicas relacionadas ao cotidiano e à experimentação, como ferramenta facilitadora do aprendizado do aluno, ${ }^{2,5}$ requer do professor amplo conhecimento e criatividade na abordagem do tema a ser trabalhado em sala de aula. Quando isto acontece, o tema não é abordado de forma clara. Portanto, se capacitarmos nossos licenciandos para que eles realmente se preparem para serem professores, visando unir os aspectos científicos e tecnológicos da Química e o ensino de sala de aula, isto se constituirá em uma ferramenta na abordagem dos conteúdos de Química no ensino médio.

Vale ressaltar que os cursos de licenciatura são pouco eficientes para a formação de professores $;^{3}$ desta forma, o método de estudo de casos como metodologia de ensino para a formação de docentes traz novas perspectivas para a melhoria do processo de ensinoaprendizagem, principalmente àqueles docentes que irão lecionar Físico-Química no ensino médio.

A implementação de estratégias que aproximam o professor formador/ graduandos/professor do ensino médio minimizaria a cisão entre os aspectos tecnológicos e científicos da Química com a docência em sala de aula. ${ }^{5,18,37}$ Além das estratégias de intervenção mostradas ao longo do texto, destacamos que os cursos de formação continuada para as escolas de nível médio, realização de seminários, acesso e utilização de materiais inovadores produzidos por grupos de pesquisa de divulgação científica e Ensino de Química, mudanças nos procedimentos de ensino e utilização de recursos didáticos contribuem para uma formação diferenciada do licenciando em Química.

\section{CONCLUSÃO}

As escolas públicas de Fortaleza afastam-se das experimentações, devido ao alto custo de manutenção dos laboratórios ou inexistência deles. Desta forma, as práticas relacionadas ao cotidiano, que relatem aspectos científicos e tecnológicos como ferramenta facilitadora do aprendizado do aluno, requerem do professor amplo conhecimento e 
criatividade na abordagem do tema a ser trabalhado, porém, melhoram a aprendizagem do aluno de nível médio.

A metodologia empregada consistiu em um estudo de caso que propiciou a modificação do método tradicional, utilizando-se temas como, por exemplo, o biodiesel, em que os conteúdos foram expostos de forma criativa e contextualizada. Tal proposta foi aplicada e verificou-se que há uma boa aceitação e assimilação do conhecimento sobre os temas, o que facilitou o entendimento dos conceitos da Química enunciados por parte dos alunos do ensino médio. No entanto, ainda há uma resistência por parte dos licenciandos em discutir sobre o tema, por falta de conhecimento, interesse ou justificarem que o tema não faz parte do cotidiano das escolas públicas. Através desse estudo, demonstrou-se que se pode inserir uma proposta contextualizada, de boa receptividade por parte dos alunos, uma vez que o conhecimento foi facilitado.

Conclui-se, a partir do estudo de caso, que a experimentação é válida e motiva o interesse do corpo discente para o estudo de conceitos relacionados à Química, em comparação com a metodologia tradicional utilizada no ensino médio, tornando a aprendizagem satisfatória e interessante. Ações como assistência aos professores, durante a graduação, no desenvolvimento de suas estratégias de ensino e avaliação facilitaria uma interação entre os diferentes níveis de ensino.

\section{AGRADECIMENTOS}

Ao Dr. A. Valentini pelas sugestões para o desenvolvimento do trabalho. Agradecemos também à UFC pela bolsa de monitoria concedida.

\section{REFERÊNCIAS}

1. Driver, R.; Asoko, H.; Leach, J.; Mortimer, E.; Schott, P.; Educational Research 1994, 23, 5 .

2. Maldaner, O. A.; A Formação Inicial e Continuada de Professores de Química: Professores/Pesquisadores, Ed. Ijuí: Ijuí, 2003.

3. Schnetzler, R. P.; Aragão, R. M. R.; Química Nova na Escola 1995, nº $1,27$.

4. Lima, M. E. C. C.; David, M. A.; Magalhães, W. F.; Química Nova na Escola 2008, n 29, 24.

5. Schnetzler, R.; Quim. Nova 2002, 25, 14.

6. Lopes, A. R. C.; Quim. Nova 1997, 20, 563.

7. Massi, L.; dos Santos, G. R.; Ferreira, J. Q.; Queiroz, S. L.; Quim. Nova 2009, 32, 503 .

8. Rodrigues, D. H. S.; Oliveira, A. C.; Quim. Nova 2009, 32, 250.

9. Santos, G. R.; Sá, L. P.; Queiroz, S. L.; Quim. Nova 2006, 29, 1121.

10. Sá, L. P.; Francisco, C. A.; Queiroz, S. L.; Quim. Nova 2007, 30, 731.

11. Lantz, J. M.; Walczak, M. M.; Chem. Educator 1997, 1, 1.

12. Al-Khlaifat, A.; AlRifai, R.; Chem. Educator 2002, 7, 384.

13. Belt, S. T.; Leisvik, M. J.; Hyde, A. J.; Overton, T. L.; Chemistry Education Research and Practice 2005, 6, 166.
14. Brink, C. P.; Goodney, D. E.; Hudak, N. J.; Silverstein, T. P.; J. Chem. Educ. 1995, 72, 530.

15. Challen, P. R.; Brazdil, L. C.; Chem. Educator 1996, 1, 1.

16. Cheng, V. K. W.; J. Chem. Educ. 1995, 72, 525.

17. Sá, L. P.; Queiroz, S. L.; Estudo de casos no ensino de química, Editora Átomo: São Paulo, 2009.

18. Merriam, S. B.; Qualitative Research and Case Study Applications in Education, Jossey-Bass: San Francisco, 1998.

19. Prophet, R. B.; Vlaardingerbroek, B.; Int. J. Educ. Develop. 2003, 23, 275.

20. Bennett, N.; Cornely, K.; J. Chem. Educ. 2001, 78, 759.

21. Howald, R. A.; J. Chem. Educ. 1999, 76, 208.

22. Breslin, V. T.; Sanudo-Wilhelmy, S. A.; J. Chem. Educ. 2001, 78, 1647.

23. Holman, J.; Pilling, G.; J. Chem. Educ. 2004, 81, 373.

24. McGarvey, D.; University Chemistry Education 2004, 8, 58.

25. Cornely, K.; J. Chem. Educ. 1998, 75, 475.

26. Erduran, S.; Simon, S.; Osborne, J.; Science Education 2004, 88, 915.

27. Neto, A. J.; Revista Electrónica de Enseñanza de las Ciencias 2005, 7 , 1.

28. Summerfield, S.; Overton, T.; Belt, S.; Anal. Chem. 2003, 75, 181A.

29. Tsaparlis, G.; Gorezi, M.; Canadian Journal of Science, Mathematics, and Technology Education 2005, 5, 111.

30. Velloso, A. M. S.; Sá, L. P.; Motheo, A. J.; Queiroz, S. L.; Revista Electrónica de Enseñanza de las Ciencias 2009, 8, 593.

31. Cornely, K.; J. Chem. Educ. 2001, 78, 759.

32. Herreid, C. F.; J. Col. Sci. Teach. 1998, 27, 163.

33. Curtius, A. J.; Seibert, E. L.; Fiedler, H. D.; Ferreira, J. F.; Vieira, P. H. F.; Quim. Nova 2003, 26, 44.

34. de Oliveira, M. R. C.; Martins, J.; Quim. Nova 2003, 26, 5.

35. Cunha, A. M.; Tunes, E.; da Silva, R. R.; Quim. Nova 2001, 24, 262.

36. Menezes, L. C.; Formar Professores: Tarefa da Universidade, Brasiliense: São Paulo, 1986.

37. Galiazzi, M. C.; Rocha, J. M. B.; Schmitz, L. C.; Souza, M. L.; Giesta, S.; Gonçalves, F. P.; Ciências e Educação 2001, 7, 249.

38. Franco, A. L. S. J.; Dissertação de Mestrado, Universidade Federal de São Carlos, Brasil, 2006.

39. Rinaldi, R.; Garcia, C.; Marciniuk, L. L.; Rossi, A. V.; Schuchardt, U.; Quim. Nova 2007, 30, 1374.

40. Atkins, P.; de Paula, J.; Físico-Quimica, $7^{\mathrm{a}}$ ed., LTC: Rio de Janeiro, 2004, vol. 1.

41. Castellan, G. W.; Físico-Quimica, 2a ed., LTC: Rio de Janeiro, 1986.

42. Domingues, S. F.; As experiências em Química, Edart Ed. Ltda.: São Paulo, 1975.

43. dos Santos Filho, P. S.; Quim. Nova 2000, 23, 699.

44. de Farias, R. F.; Quim. Nova, 2003, 26, 139.

45. Pfundt, H.; Deut, R.; Bibliography: Students alternative frameworks and science education, $3^{\text {rd }}$ ed., Kill and IPN: New York, 1991.

46. http://portal.mec.gov.br/cne/arquivos/pdf/2001/pces1303_01.pdf., acessada em Janeiro 2009. 